\title{
Uveal melanoma
}

INSERM

\section{Source}

INSERM. (1999). Orphanet: an online rare disease and orphan drug data base. Uveal melanoma. ORPHA:39044

Uveal melanoma is a rare tumor of the eye, arising from the choroid in $90 \%$ of cases and from the iris and ciliary body in the other $10 \%$ of cases, which clinically presents with visual symptoms (including blurred vision, photopsia, floaters, and visual field reduction), a visible mass and pain. Fatal metastatic disease is seen in about half of all patients, with the liver being the most frequent site of metastasis. 